This is an author produced version of a paper published in Documenta Ophthalmologica. This paper has been peer-reviewed but does not include the final publisher proof-corrections or journal pagination.

Citation for the published paper:

Kjellstrom, Sten and Bruun, Anitha and Isaksson, Bjorn and Eriksson, T and Andreasson, Sten and Ponjavic, Vesna.

"Retinal function and histopathology in rabbits treated with Topiramate" Documenta Ophthalmologica, 2006, Vol: 113, Issue: 3, pp. 179-86. http://dx.doi.org/10.1007/s10633-006-9027-8

Access to the published version may require journal subscription.

Published with permission from: SpringerLink 


\section{Retinal function}

\section{and histopathology in rabbits treated with Topiramate}

S Kjellström M.D. ${ }^{1}$, A Bruun Ph.D. ${ }^{1}$, B Isaksson MsC.Pharm. ${ }^{2}$, T Eriksson MsC.Pharm. ${ }^{2}$,

S Andréasson M.D., Ph.D ${ }^{1}$, V Ponjavic M.D., Ph.D ${ }^{1}$

${ }^{1}$ Dept. of Ophthalmology, University of Lund, Lund, Sweden.

${ }^{2}$ Hospital Pharmacy, University of Lund, Lund, Sweden

Disclosure: The authors have reported no conflicts of interest.

Short title: Topiramate effects in rabbit retina

\section{Correspondence and proofs to:}

Vesna Ponjavic, Department of Ophthalmology, University of Lund, S 22185 Lund, Sweden Fax: +46-46-13 9045

E-mail: vesna.ponjavic@med.lu.se 


\section{Abstract}

Purpose: To evaluate retinal function and histopathology in rabbits treated orally with the antiepileptic drug topiramate.

Methods: Six rabbits were treated with a daily oral dose of topiramate orally during a period of eight months. Six rabbits receiving water served as controls. Blood samples were analyzed for determination of topiramate serum levels in order to ensure successful drug exposition. Standardized full-field electroretinograms (ERGs) were performed before treatment and then at 2, 3 and 8 months during the treatment period. After terminating treatment the rabbits were sacrificed and the morphology of the sectioned retina was studied.

Results: After eight months of treatment the full-field ERG demonstrated normal rod function in treated and control rabbits, but the light adapted $30 \mathrm{~Hz}$ flicker b-wave amplitude was significantly reduced in the treated rabbits. This was the case for both the light adapted (Wilcoxon signed ranks test, $\mathrm{p}=0.046$ ) and the dark adapted (Wilcoxon signed ranks test, $\mathrm{p}=0.028) 30 \mathrm{~Hz}$ flicker response from the treated rabbits. Retinal immunohistology revealed a severe accumulation of GABA in amacrine cells and in the inner plexiform layer in 4 of 6 treated rabbits compared to the controls. Conclusions: Topiramate, orally administrated to rabbits, may cause a significant reduction of the retinal function demonstrated by the reduced b-wave amplitude in the full-field ERG, as well as changes in immunohistology characterized by a severe accumulation of GABA in the inner retina. The retinal dysfunction and the morphological changes indicate that topiramat may damage the retina, similarly to vigabatrin (another anti-epileptic drug).

Keywords: Topiramate, electroretinogram, immunohistochemistry, drug toxicity, rabbit. 


\section{Introduction}

Topiramate, an antiepileptic drug, is frequently used in the management of refractory epilepsy, not satisfactory controlled by traditional anticonvulsants. It is known to significantly increase human cerebral gamma-aminobutyrate (GABA) thereby increasing the threshold for seizure activity. Several different mechanisms of action are involved, such as blocking of sodium channels, enhancement of GABA-mediated chloride fluxes across the post-synaptic membrane, positive modulation of GABA-A receptors and a mild inhibition of carbonic anhydrase.$^{1,2}$ Another antiepileptic drug that increases cerebral GABA-levels is vigabatrin (inhibits GABA-transaminase), which has been shown to cause severe, persistent visual field constriction. ${ }^{3-6}$ Several electrophysiological studies of patients treated with vigabatrin, have demonstrated reduced photopic amplitudes indicating actual dysfunction of an unspecified cell level in the retina. ${ }^{7-8}$ We have previously shown that the visual field defect (typically a bilateral nasal-inferior constriction) in patients treated with vigabatrin, is actually correlated with changes in the full-field electroretinogram (ERG) characterized by a reduced $30 \mathrm{~Hz}$ flicker response and a preserved scotopic response. ${ }^{9}$

Initially, complex epilepsy was the only indication for treatment with topiramate. Recently it has been suggested that topiramate may be useful in the treatment of obesity ${ }^{10-15}$, eating disorders ${ }^{16-20}$, migraine $^{21-31}$, bipolar disorders ${ }^{32-35}$, other psychiatric disorders ${ }^{36-42}$, alcohol dependence ${ }^{43-47}$ and other addictive disorders ${ }^{48}$. Also the drug is more frequently used in the management of childhood epilepsy $^{49-51}$.

The objective of the present study was to evaluate retinal function and morphology, in rabbits treated orally with topiramate during a period of 8 months, which in humans would correspond to a period of approximately 20 years.

\section{Material and methods}

\section{Subjects and medication}

Kjellström et al. Topiramate effects in rabbit retina 
Seven fully grown rabbits (body weight $4-5 \mathrm{~kg}$ ) were treated with a daily oral dose of topiramate during a period of 8 months. Nine rabbits receiving water were included as controls and were examined according to the protocol used for the treated rabbits. All rabbits (treated subjects and controls) were seven months old on entry to the study. One treated rabbit and three controls died unexpectedly during the study, and were therefore excluded.

In previous studies a suspension of topiramate in aqueous $0.5 \%$ sodium carboxymethyl-cellulose (CMC) has been dosed via gastric intubation in rabbits (Janssen-Cilag AB, Sollentuna, Sweden). Suspensions of topiramate, at concentrations of 1 and $75 \mathrm{mg} / \mathrm{mL}$, in $0.5 \%$ CMC have been shown to be stable for at least 5 weeks at $4^{\circ} \mathrm{C}$ and $25^{\circ} \mathrm{C}$ (Janssen-Cilag AB,Sollentuna, Sweden). A dose of $20 \mathrm{mg} / \mathrm{kg} /$ day in rabbits has been suggested to be equivalent to the human therapeutic dose of topiramate (Janssen-Cilag AB, Sollentuna, Sweden). Therefore, suspensions of topiramate tablets $50 \mathrm{mg} / \mathrm{mL}$ in $0.5 \%$ CMC were prepared for 5 weeks at a time and the initial dosage of this preparation was $0.4 \mathrm{~mL} / \mathrm{kg} /$ day (=20mg/kg/day), thus the rabbits (body weight $4-5 \mathrm{~kg}$ ) received approximately 80-100mg topiramate on one occasion every day. The suspensions were stored in room temperature and given orally using a syringe.

Concentrations of topiramate in serum were measured on two occasions during the treatment period, in order to ensure successful drug exposition. Blood samples were collected from the ear-vein of the rabbits. The individual drug dose was adjusted depending on the presence or absence of drug side-effects (loss of appetite). This study was conducted by acceptance from the ethical committee for animal research at the University of Lund. The research procedures were in accordance with the ARVO statement for the use of animals in ophthalmic and vision research.

\section{Electrophysiology}

Standardized full-field electroretinography (ERG) (slightly modified for rabbit ERG ${ }^{53}$ ) was assessed on three occasions prior to treatment and on three occasions during treatment (2 months, 3 months and eight months after initiating treatment). The ERGs were recorded with a Nicolet 
analysis system (Nicolet Biomedical Instruments, Madison Wisconsin) as described previously. ${ }^{52-}$ 53 , The examinations were conducted according to the International Society for Clinical Electrophysiology of Vision (ISCEV) standards. ${ }^{54}$ The right eye was tested after maximal pupil dilation with topical 1\% cyclopentolate hydrochloride, and after at least 30 minutes of dark adaptation. A Burian-Allen bipolar ERG contact lens electrode was applied on the topically anesthetized cornea together with a sub-cutaneous ground electrode on the neck. Responses were obtained with a wide band filter (-3dB at $1 \mathrm{~Hz}$ and $500 \mathrm{~Hz}$ ), stimulating with single full field flashes (30 $\mu \mathrm{s})$ with dim blue light (Wratten filters \#47, 47A and 47B), and with white light (integrated luminance 0.81cd$\mathrm{s} / \mathrm{m}^{2}$ ). Responses from $30 \mathrm{~Hz}$ flickering white light (integrated luminance $0.81 \mathrm{~cd}-\mathrm{s} / \mathrm{m}^{2}$ ) averaged from 20 sweeps with no background illumination, and with background illumination $\left(34 \mathrm{~cd} / \mathrm{m}^{2}\right)$ until two successive identical curves were obtained. ${ }^{53}$ Oscillatory potentials were recorded from the dark adapted eye, with white light (integrated luminance $0.81 \mathrm{~cd}-\mathrm{s} / \mathrm{m}^{2}$ ) and by applying an overall band pass filter from $100 \mathrm{~Hz}$ (low frequency filter - LFF) to $300 \mathrm{~Hz}$ (high frequency filter HFF). The referred luminance of the different light stimuli has been measured from a photometer on the light reflected from the Ganzfeld sphere. At each stimulus intensity the recording were repeated to ensure reproducibility (ie until two successive identical curves were obtained), but no stimuli was repeated at intervals less than $0.5 \mathrm{~s}$. All rabbits were sedated with Hypnorm $0.6 \mathrm{ml}$ (fentanylcitrate $0.315 \mathrm{mg} / \mathrm{ml}$ and fluanisone $10 \mathrm{mg} / \mathrm{ml}$,VetaPharma Ltd, Leeds, UK) during the examination.

\section{Tissue preparation}

The rabbits were euthanized by an intravenous overdose of barbiturates. The eyes were enucleated within one minute and fixed for 30 minutes in freshly prepared 4\% phosphate buffered formaldehyde, generated from paraformaldehyde (Merck, Darmstadt, Germany) at pH 7.4 in 0.1 
M Sörensen’s phosphate buffer (primary and secondary NaHPO; Merck). The eyes were then transected at the ora serrata. The anterior segment, lens and vitreous body were discarded. The posterior segment were postfixed in the same fixative for 3,5 hours, at $4^{\circ} \mathrm{C}$. The tissue was then rinsed and cryoprotected by transferring it stepwise through solutions of increasing concentrations of sucrose (10, 15 and 20\%) in the Sörensen's buffer. The eyecups were then divided into two parts by a vertical incision from the superior to the inferior retinal margins comprising the optic disc. The two halves were embedded in Yazulla media (30\% egg albumen and $3 \%$ gelatine in water) and then sectioned $(12 \mu)$ in the cryostat $\left(-21^{\circ} \mathrm{C}\right)$ starting at the central part and moving towards the peripheral part of the eye. The sections were collected on chrome alum coated slides, air dried, and stored at $-20^{\circ} \mathrm{C}$ until used.

\section{Immunohistochemistry}

The sections were thawed and washed in $0.1 \mathrm{M}$ sodium phosphate buffered saline pH 7,2 (PBS) with $0.25 \%$ Triton X-100 (PBST). For diluting the primary and secondary antibodies, 1\% bovine serum albumin was added in PBST. The sections from the eyes were then incubated in the primary antibodies vimentin, GFAP and GABA (targeting Müllercells, gliacells and GABA ergic cells, respectively), for $16-18 \mathrm{hrs}$, in $4^{\circ} \mathrm{C}$. After rinsing, the slides were mounted in a custom made antifading mounting media. The slides were examined using immunofluorescence imaging and photographed by a digital camera (Nikon Eclipse 800).

\section{Results}

\section{Medication}

Because of loss of appetite, a known adverse effect of topiramate, we were forced to adjust the doses of the medication depending on how the individual rabbit tolerated the drug. In all treated rabbits serum topiramate levels were within the range of $3.24-15.87 \mu \mathrm{mol} / \mathrm{L}$ when treatment was tolerated, and low or undetectable $(<2.8 \mu \mathrm{mol} / \mathrm{L})$ when the dose was reduced because of loss of 
appetite. The drug tolerance in the treated rabbits varied considerably which is demonstrated by the range of topiramate serum concentrations. At first time point for measuring topiramate concentration (2,5 months of treatment) four rabbits had elevated concentrations, which were the same rabbits as those with histopathological changes (Table). Up to this timepoint all treated rabbits had the same dose of topiramate, which was later reduced because of side effects.

\section{Electrophysiology}

Five different full-field ERG responses (dark adapted and light adapted) from one of the rabbits (2A-041) are presented in Figure 1. The figure shows a selective reduction of the $30 \mathrm{~Hz}$ flicker reponse, both dark- and light adapted, in contrast to the rod response that remains unaffected. Initially, before treatment the fullfield ERG results were similar in the six treated rabbits and in the six controls. After eight months of treatment the full-field ERG (last examination) demonstrated normal rod function in treated and control rabbits, but a significantly reduced light adapted $30 \mathrm{~Hz}$ flicker response in treated rabbits (Wilcoxon signed ranks test, $\mathrm{p}=0.046$ ). Comparison in the treated group before and after treatment demonstrated a significant difference in the light adapted, and the dark adapted 30Hz flicker response and for P1, P2, P3 in the oscillatory potentials (Wilcoxon signed ranks test, $\mathrm{p}=0.028$ ).

Full-field ERG b-wave amplitudes from all treated rabbits, resulting from stimulation with dim blue light single flash (selective rod response), white light single flash (total retinal response) and $30 \mathrm{~Hz}$ flicker white light dark and light adapted, before and after treatment, are presented in the the Table. All treated rabbits demonstrated reduced $30 \mathrm{~Hz}$ flicker responses after treatment, which is also shown (for one rabbit) in Fig. 1. Also the oscillatory potential (OP) amplitudes were significantly reduced after treatment (Table). There was no difference in implicit time for the 30 $\mathrm{Hz}$ flicker white light stimulation, before and after treatment.

\section{Histology of retina}

\section{$G A B A$}

Kjellström et al. Topiramate effects in rabbit retina 
The retinal sections presented (Fig 2) are from two controls and all treated rabbits. In four of the treated animals, significant pathology in immunostaining could be identified in the retinal sections. The immunoreactivity was enhanced in the amacrine cells. GABA-positive cellbodies appeared in the inner nuclear layer (INL) and among the ganglion cells (GGL). In the inner plexiform layer (IPL) the staining was strong, and no clear layering could be seen (Fig. 2). In the retina of the control animals and in two treated animals the amacrine cells in the INL were moderately immunoreactive, and a clear layering could be seen in the IPL.

\section{GFAP and vimentin}

The staining with GFAP and vimentin did not show any significant differences between treated rabbits and controls.

\section{Discussion}

Antiepileptics are given to a broad population as the worldwide annual incidence of epilepsy ranges from 24-53/100 000. ${ }^{55}$ Adverse effects of antiepileptics are continuously being studied and reported, especially since vigabatrin, an carbanhydraes blocker was found to cause severe and probably irreversible visual field defects. ${ }^{3-6}$

In comparison, topiramate has not as frequently been associated with visual field defects. In higher doses it is known to cause other visual disturbances such as acute angle closure glaucoma and diplopia/nystagmus. ${ }^{56}$ So far 14 reports (up to september 2005) of non characteristic visual field defects have been submitted to the World Health Organisation (WHO) collaborating Centre for International Drug Monitoring, some of which have been determined to have a possible association with topiramate. In a recently published case report the authors describe a patient with an incongruent homonymous hemianopsia possibly caused by topiramate. ${ }^{57}$ Another case was reported recently describing a patient with bilaterally constricted visual fields verified by a reduced multifocal electroretinogram indicating a diffuse retinal dysfunction possibly caused by 
topiramate. $^{58}$ In the present study we have demonstrated alterations in the full-field ERG in topiramate treated rabbits similar to the previously reported alterations in retinal function and morphology caused by vigabatrin. ${ }^{52}$ These results indicate that topiramate may also have adverse effects on retinal function which in turn may cause visual field defects.

The pathogenesis behind this retinal dysfunction is still unknown. We have previously found glial cell pathology in vigabatrin treated rabbits. ${ }^{52}$ In the present study the histopathology results were similar showing in 4 of 6 treated rabbits a pathological immunohistology, mainly a severe accumulation of GABA in amacrine cells and in the inner plexiform layer. This was not seen in all treated rabbits, which may indicate that the reduced function precedes the immunohistochemical pathology. However, the four rabbits with histopathological changes in retinal sections, also had significantly elevated concentrations of topiramate in serum after 2 months of treatment. Adverse effects in the retina are important to investigate because of a continuous widening of indications for treatment with topiramate, from complex epilepsy being the only indication only a few years ago, to currently testing treatment for several other diagnoses such as migraine, bipolar disorders, eating disorders and obesity ${ }^{10-48}$. The results from this study indicate that some caution should be taken until further studies have revealed the toxicology pattern for this drug. Also patients should be aware of these ocular side effects, and a full-field ERG performed on every patient reporting visual disturbance.

We conclude that topiramate, orally administrated to rabbits, may cause a significantly reduced retinal function reflected by the diminished b-wave amplitude in the full-field ERG, which has previously not been reported. Retinal histopathology in treated rabbits correlated significantly with serum levels of topiramat, but not totally with the reduced retinal function. Further toxicological studies, including objective evaluation of retinal function, are needed as the indications for treatment with topiramate are numerous today. 


\section{Acknowledgements}

We thank Ing-Marie Holst and Boel Nilsson for skillful technical assistance. This study was supported by grants from Stiftelsen Synfrämjandets Forskningsfond, Kronprinsessans Margaretas Arbetsnämnd, the Swedish Medical Research Council (project no. 73X-12597-03A), the $2^{\text {nd }}$ ONCE international award for new technologies for the blind and the Faculty of Medicine at the University of Lund.

\section{References}

1. Roff Hilton EJ, Hosking SL, Betts T. The effect of antiepileptic drugs on visual performance. Seizure 2004;13:113-128.

2. Czapinski P, Blaszczyk B, Czuczwar SJ. Mechanism of action of antiepileptic drugs. Current topics in Medical Chemistry 2005;5:3-14.

3. Eke T, Talbot JF, Lawden MC. Severe persistent visual field constriction associated with vigabatrin. Br Med J 1997;314:180-181.

4. Harding GA. Severe persistent visual field constriction associated with vigabatrin (letter). Br Med J 1997;314:1694.

5. Wilson EA, Brodie MJ. Severe persistent visual field constriction associated with vigabatrin (letter). Br Med J 1997;314:1693.

6. Steinhoff J, Freudenthaler N, Paulus W. The influence of established and new epileptic drugs on visual perception. Epilepsy Res 1997;29:34-47.

7. Harding GF, Wild JM, Robertson KA, et al. Separating the retinal electrophysiological effects of vigabatrin: treatment versus field loss. Neurology 2000;55:347-352. 
8. Coupland SG, Zackon DH, Leonard BC, Ross TM. Vigabatrin effect on inner retinal function. Ophthalmology 2001;109:1493-1498.

9. Ponjavic V, Andréasson S. Multifocal ERG and full-field ERG in patients on long-term vigabatrin medication. Doc Ophthalmol 2001;102:63-72.

10. Wilding J. Clinical evaluation of anti-obesity drugs. Cuu Drug Targets 2004;5:325-332.

11. Ioannides-Demos LL, Proietto J, McNeil JJ. Pharmacotherapy for obesity. Drugs 2005;65:1391-1418.

12. Kaplan LM. Pharmacological therapies for obesity. Gastroenterol Clin North Am. 2005;35:91-104.

13. Li Z, Maglione M, Tu W, et al. Meta-analysis: pharmacologic treatment of obesity. Ann Intern Med. 2005; 142:532-546.

14. Halpern A, Mancini MC. Diabesity: are weight loss medications effective? Treat Endocrinol. 2005;4:65-74.

15. Norris SL, Zhang X, Avenell A, Gregg E, Schmid CH, Lau J. Pharmacotherapy for weight loss in adults with type 2 diabetes mellitus. Cochrane Dtbase Syst Rev. 2005;CD004096.

16. Pederson KJ, Roerig JL, Mitchell JE. Towards the pharmacotherapy of eating disorders. Expert Opin Pharmacother. 2003;4:1659-1678.

17. Hedges DW, Reimherr FW, Hoopes SP, et al. Treatment of bulimia nervosa with topiramate in a randomized double-blind, placebo-controlled trial, part 2: improvement in psychiatric measures. J Clin Psychitry 2003;64:1449-1454.

18. Appolinarion JC, McElroy SL. Pharmacological approaches in the treatment of binge eating disorder. Curr Drug Trgets. 2004;5:301-307.

19. De Bernardi C, Ferraris S, D’Inella P, Do F, Torre E. Topiramate for binge eating disorder. Prog Neuropsychopharmacol Biol Psychiatry. 2005;29:339-341.

20. Winkelman JW. Treatment of nocturnal eating syndrome and sleep-related eating disorder with topiramate. Sleep Med. 2003;4:243-246.

21. Pappagallo M. Newer antiepileptic drugs: possible uses in the treatment of neuropathic pain and migraine. Clin Ther. 2003;25:2506-2538. 
22. Lewis DW, Dimond S, Scott D, Jones V. Prophylactic treatment of pediatric migraine. Headache. 2004;44:230-237.

23. Diamond M, Dahlof C, Papadopoulos G, Neto W, Wu SC. Topiramate improves healthrelated quality of life when used to prevent migraine. Headache. 2005;45:1023-1030.

24. Blumenfeld A. Clinical approaches to migraine prophylaxis. Am J Manag Care. 2005;11:S55-61.

25. Brown JS, Papadopoulos G, Neumnn PJ, Friedman M, Miller JD, Menzin J. Costeffectiveness of topiramate in migraine prevention: results from a pharmacoeconomic model of topiramate treatment. Headache. 2005;45:1012-1022.

26. Bussone G, Diener HC, Pfeil J, Schwlen S. Topiramate 100md/day in migraine prevention: pooled analysis of double-blind randomized controlled trials. Int J Clin Pract. 2005;59:961968.

27. D’Amico D, Grzzi L, Usai S, Moschiano F, Bussone G. Topiramate in migraine prophylaxis. Neurol Sci. 2005;26:130-133.

28. Silberstein SD. Preventive treatment of headaches. Curr Opin Neurol. 2005;18:289-292.

29. Brandes JL. Practical use of topiramate for migraine prevention. Headache. 2005;45:66-73.

30. White HS. Molecular pharmacology of topiramate: managing seizures and preventing migraine. Headache. 2005;45:S48-56.

31. Campistol J, Campos J, Casa C, Herranz JL. Topiramate in the prophylactic treatment of migraine in children. J Child Neurol. 2005;20:251-253.

32. Wang PW, Ketter TA, Becker OV, Nowakowska C. New anticonvulsant medication uses in bipolar disorder. CNS Spectr. 2003;8:941-947.

33. Dunner DL. Safety and tolerability of emerging pharmacological treatments for bipolar disorder. Bipolar Disord. 2005;7:307-325.

34. Gajwani P, Fortshoff A, Muzina D, et al. Antiepileptic drugs in mood-disordered patients. Epilepsia. 2005;46:38-44.

35. Vieta E. Bipolar mixed states and their treatment. Expert Rev Neurother. 2005;5:63-68. 
36. Janowsky DS, Kraus JE, Barnhill J, Elmir B, Davis JM. Effects of topiramate on aggressive, self-injurious, and disruptive/destructive behaviors in the intellectually disabled, an open-label retrospective study. J Clin Psychopharmacol. 2003;23:500-504.

37. Gatto EM, Roca MC, Raina G, Micheli F. Low doses of topiramate are effective in essential tremor: a report of three cases. Clin Neuropharmacol. 2003;26:294-296.

38. Fhager B, Meiri IM, Sjogren M, Edman A. Treatment of aggressive behavior in dementia with the anticonvulsant topiramate: a retrospective pilot study. Int Psychogeriatr. 2003;15:307-309.

39. Asnis GM, Kohn SR, Henderson M, Brown NL. SSRIs versus non SSRIs in post-traumatic stress disorder: an update with recommendations. Drugs. 2004;64:383-404.

40. Nickel MK, Nickel C, Kpln P, et al. Treatment of aggression with topiramate in male borderline patients: a double-blind, placebo-controlled study. Biol Psychiatry 2005;57:495499.

41. Tiihonen J, Hlonen P, Wahlbeck K, et al. Topiramate add-on in treatment-resistant schizophrenia: a randomized, double-blind, placebo-controlled, crossover trial. J Clin Psychiatry. 2005;66:1012-1015.

42. Arnone D. Review of the use of topiramate for treatment of psychiatric disorders. Ann Gen Psychiatry. 2005;16:5.

43. Anderson N, Oliver MN. Oral topiramate effective for alcoholism. J Fam Pract. 2003;52:682-683, 687.

44. Raguraman J, Priyadharshini RK, Chandrasekarn. Effects of topiramate in alcohol dependence. Aust N Z J Psychiatry. 2005;39:736-737.

45. Johnson BA, Ait-Daoud N, Akhtar FZ, Jvors MA. Use of oral topiramate to promote smoking abstinence among alcohol-dependent smokers: a randomized controlled trial. Arch Intern Med. 2005;165:1600-1605.

46. Book SW, Myrick H. Novel anticonvulsants in the treatment of alcoholism. Expert Opin Investig Drugs. 2005;14:371-376.

47. Rubio G, Ponce G, Jimenez-Arriero MA, Palomo T, Manzanares J, Ferre F. Effects of topiramate in the treatment of alcohol dependence. Pharmacopsychiatry. 2005;37:37-40. 
48. Sofouglu M, Kosten TR. Novel approaches to the treatment of cocaine addiction. CNS Drugs. 2005;19:13-25.

49. Artemowitz B, Sobaniec W. Neuroprotection possibilities in epileptic children. Rocz Akad Med Bialymst. 2005;50:91-95.

50. Al Ajlouni S, Shorman A, Daoud AS. The efficacy of topiramate on refractory epilepsy in infants and young children: a multi-center clinical trial. Seizure 2005: [Epub ahead of print].

51. Hershey AD, Winner PK. Pediatric migraine: recognition and treatment. J Am Osteopath Assoc. 2005;105:2S-8S.

52. Ponjavic V, Gränse L, Kjellström S, Andréasson S, Bruun A. Alterations in electroretinograms and retinal morphology in rabbits treated with Vigabatrin. Doc Ophthalmol 2004: 00; 1-9.

53. Gjörloff K, Andréasson S, Ehinger B. Standardized full-field electroretinography in rabbits. Doc Ophthalmol 2004;109:163-168.

54. Marmor MF, Holder GE, Seelinger MW, Yamamoto S; International Society for Clinical Electrophysiology of Vision. Standard for clinical electroretinography (2004 update). Doc Ophthalmol 2004; 108: 107-114.

55. Hauser W. Incidence and prevalence. In: Engel J, Pedley T, eds. Epilepsy: a comprehensive textbook. Philadelphia: Lippincott-Raven Publishers, 1997; pp. 47-57.

56. Fraunfelder FW, Fraunfelder F. Adverse ocular drug reactions recently identified by the national registry of drug-induced ocular side effects. Ophthalmology 2004; 111: 12751279.

57. Foroozan R, Buono LM. Clinical challenges: Foggy visual field defect. Surv. Ophthalmol. 2003; 48: 447-451.

58. Vaphiades MS, Mason J. Letter to the editor: Foggy visual field defect. Surv. Ophthalmol. 2003; 49: 266-267. 


\section{Legends:}

\section{Table}

ERG data demonstrating responses (b-wave amplitudes) to five different stimulations before (upper) and after (lower) treatment with topiramate for all treated rabbits and mean values for the controls. The rabbits with positive histopathology $(+)$ had elevated levels of topiramate in serum.

\section{Figure 1}

Full-field ERG from rabbit 2A-041 before and after treatment with topiramate (December $12^{\text {th }}$ 2002 and November $19^{\text {th }}$, 2003). The ERG traces demonstrate that the responses to dim blue light (integrated luminance $0.81 \mathrm{~cd}-\mathrm{s} / \mathrm{m} 2$ ) remains unaffected by topiramate while the b-wave amplitude to $30 \mathrm{~Hz}$ flickering white light (integrated luminance $0.81 \mathrm{~cd}-\mathrm{s} / \mathrm{m} 2$ ) with no background illumination, and with background illumination $(34 \mathrm{~cd} / \mathrm{m} 2)$ are significantly reduced by the drug. The $30 \mathrm{~Hz}$ flicker response in the rabbit ERG, before treatment, contains a 2nd small positive peak, which is a flash artefact

\section{Figure 2}

GABA immunoreactivity in two controls (top row) and in the retina from all treated animals. The GABA-activity was enhanced in the inner retina: in the amacrine cells (arrow head) in the displaced amacrine cells and in the ganglion cell (arrow), in four of six treated rabbits. $\mathrm{Ph}=$ photoreceptors, inner and outer segments $\mathrm{INL}=$ inner nuclear layer, $\mathrm{ONL}=$ outer nuclear layer, GGL=ganglion cell layer. 
Table 1

\begin{tabular}{|c|c|c|c|c|c|c|c|}
\hline Rabbit & $\begin{array}{c}\text { Dim blue light } \\
\text { Amplitude } \\
(\mu V)\end{array}$ & $\begin{array}{l}\text { White light } \\
\text { Amplitude } \\
\qquad(\mu V)\end{array}$ & $\begin{array}{c}30 \mathrm{~Hz} \text { flicker } \\
\text { Amplitude } \\
(\mu \mathrm{V})\end{array}$ & $\begin{array}{c}30 \mathrm{~Hz} \text { flicker } \\
\text { Amplitude } \\
(\mu \mathrm{V})\end{array}$ & $\begin{array}{c}\text { Oscillatory } \\
\text { potentials } \\
\text { P1/ P2/ P3 } \\
\text { Amplitude } \\
(\mu V)\end{array}$ & $\begin{array}{c}\text { Topiramate } \\
\text { serum } \\
\mu \mathrm{mol} / \mathrm{L}\end{array}$ & Histopathology \\
\hline \multirow[t]{2}{*}{$2 A-040$} & 121 & 139 & 25 & 20 & $22 / 27 / 23$ & $<2.8$ & - \\
\hline & 76 & 92 & 7 & 5 & $15 / 14 / 13$ & & \\
\hline \multirow[t]{2}{*}{$2 A-032$} & 40 & 89 & 16 & 16 & $19 / 29 / 20$ & 12.23 & + \\
\hline & 74 & 98 & 6 & 6 & $11 / 15 / 12$ & & \\
\hline \multirow[t]{2}{*}{$2 A-033$} & 50 & 124 & 18 & 13 & 19/26/ 19 & 15.87 & + \\
\hline & 94 & 100 & 4 & 4 & $12 / 23 / 15$ & & \\
\hline \multirow[t]{2}{*}{ 2A-041 } & 68 & 158 & 31 & 29 & $26 / 43 / 19$ & 5.69 & + \\
\hline & 96 & 115 & 10 & 8 & $8 / 13 / 20$ & & \\
\hline \multirow[t]{2}{*}{ 2A-042 } & 130 & 202 & 33 & 26 & $34 / 50 / 36$ & 6.44 & + \\
\hline & 96 & 130 & 13 & 11 & $19 / 30 / 21$ & & \\
\hline \multirow[t]{2}{*}{ 2A-094 } & 91 & 188 & 24 & 20 & $26 / 36 / 29$ & $<2.8$ & - \\
\hline & 56 & 125 & 6 & 5 & $14 / 18 / 15$ & & \\
\hline $\begin{array}{l}\text { Six } \\
\text { controls } \\
\text { Mean } \pm \\
\text { STD }\end{array}$ & $94 \pm 45$ & $161 \pm 68$ & $20.1 \pm 7.1$ & $15.5 \pm 7.1$ & $\begin{array}{c}24 \pm 11 / 31 \pm 15 / \\
24 \pm 12\end{array}$ & & \\
\hline
\end{tabular}




\section{Before treatment After treatment}

\section{Darkadapted}

Blue light

Combined response

Oscillatory potentials

$30 \mathrm{~Hz}$ flicker responses

\section{Lightadapted}

$30 \mathrm{~Hz}$ flicker responses
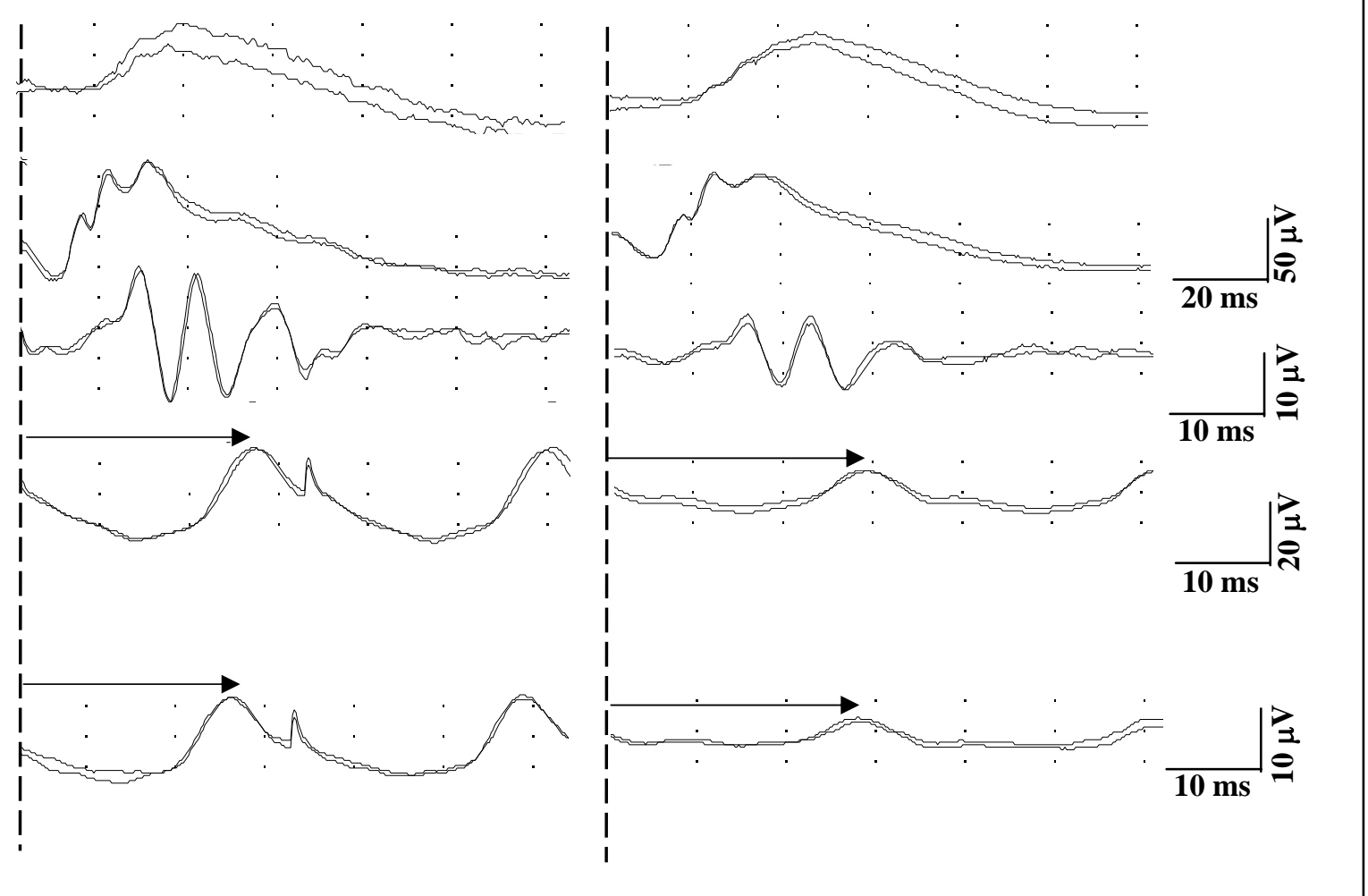
Control

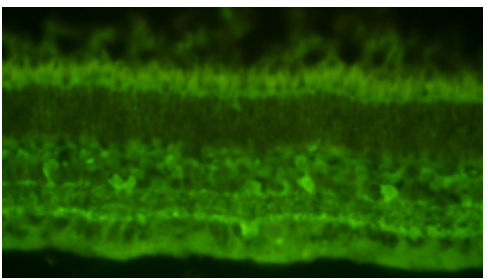

$2 \mathrm{~A}-040$

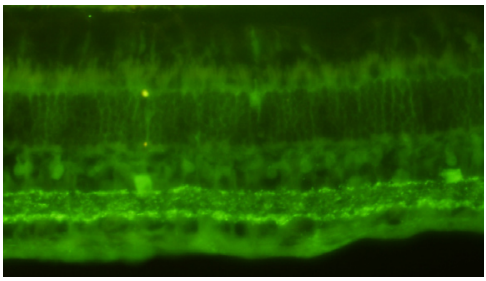

2A-033

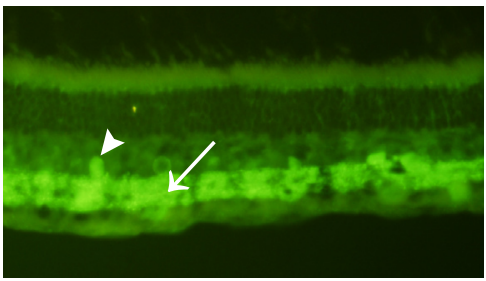

2A-032

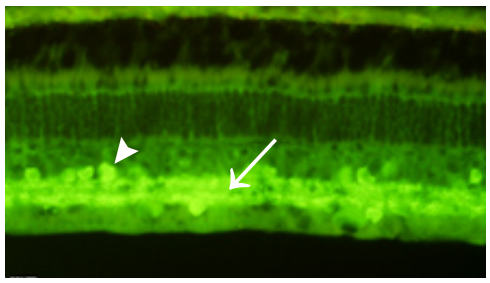

Control

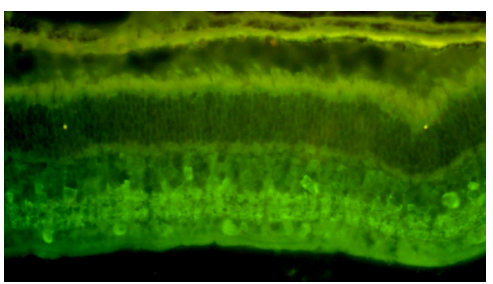

$\mathrm{Ph}$

ONL

INL

GGL

\section{A-094}

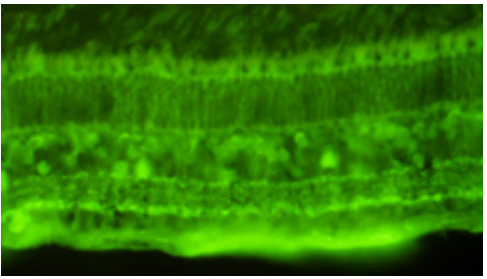

$\mathrm{Ph}$

ONL

INL

GGL

\section{A-041}

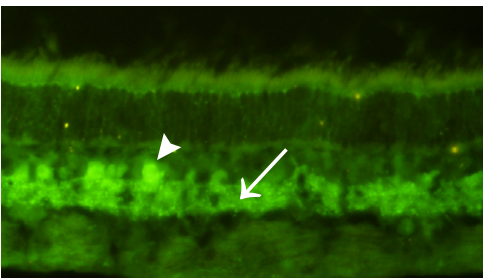

$\mathrm{Ph}$

ONL INL

GGL

\section{A-042}

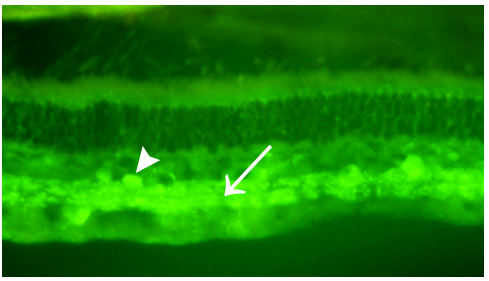

$\mathrm{Ph}$

ONL INL

GGL 